удК 331:658

\title{
ТРАНСФОРМАЦИЯ ПРЕДСТАВЛЕНИЙ О РОЛИ СОЦИАЛЬНОСТИ В УПРАВЛЕНИИ ЧЕЛОВЕЧЕСКИМИ РЕСУРСАМИ И КОНЦЕПЦИЯ ДОВЕРИЯ
}

\author{
Каз Евгения Михайловна, \\ gk123a@mail.ru \\ Национальный исследовательский Томский государственный университет, \\ Россия, 634050, г. Томск, пр. Ленина, 36
}

Каз Евгения Михайловна, кандидат экономических наук, доцент кафедры стратегического менеджмента и маркетинга Института экономики и менеджмента Томского государственного университета.

\begin{abstract}
Актуальность. В 1903 г. Ф.У. Тейлор писал, что причиной низкой производительности труда являются мысли и рассуждения, обусловленные общественными отношениями между предпринимателями и рабочими, и считал, что при условии их сотрудничества, взаимной помощи производительность последних может быть увеличена в среднем почти вдвое [1]. Проблема, сформулированная Ф.У. Тейлором, и поставленный им вопрос «Какие иные реформы... могут дать столько в направлении повышения благосостояния, уменьшения нищеты и облегчения страданий?» уже более ста лет оказывают мощное влияние на содержание исследовательских программ в области менеджмента. Однако многие из намеченных Ф.У. Тейлором задач все еще далеки от своего решения. Период социально-экономической нестабильности, вновь переживаемый страной в настоящее время, усиливает потребность в инструментах, активизирующих способность и готовность сотрудников выполнять возложенные на них задачи в условиях динамично изменяющейся внешней и внутренней среды. Цель исследования: проанализировать изменение представлений о роли социальности в системе знаний, требующее формирования новых подходов в управлении человеческими ресурсами. Методы: сравнение, обобщение и систематизация, в работе также используется аксиологический подход, предполагающий ценностное измерение исследуемых социокультурных явлений. Результаты: представлена система аргументов, свидетельствующих об усилении роли доверия как в организации общественной жизни в целом, так и в деятельности организации в частности. Показано, что «доверие» способствует упорядочению социальных взаимодействий в условиях трансформационных изменений (нарастания неопределенности и рисков в деятельности компании), когда снижаются возможности «уверенности» и «веры» как механизмов организации социальной жизни. Возрастанию роли фактора «доверие» также способствуют разделение труда, делегирование полномочий, сложность и «непрозрачность» организационных и технических систем. Вывод: более существенную роль начинает играть фактор «доверие» в функционировании системы управления организащией.
\end{abstract}

Ключевые слова: Управление организацией, доверие, человеческие ресурсы, трансформация социальности, социально-психологические аспекты управления.

О дистанции, пройденной в вопросе осмысления роли «социальности» в трудовой деятельности, от понимания работника как «живого двигателя» и «фактора производства» до наших дней, свидетельствует фраза, принадлежащая Ф. Фукуяме, одному из наиболее влиятельных общественных мыслителей современности: «Сотрудники компании никогда не будут лишь пунктами в организационном расписании: на рабочем месте у них развиваются чувства солидарности, преданности, антипатии - все то, что влияет на саму природу хозяйственной деятельности, которой компания занимается. Другими словами, социальное... поведение сосуществует с рациональным стремлением к максимизации полезности в целом ряде аспектов. Поэтому наибольшая экономическая эффективность не обязательно достигается рациональными и эгоистически 
настроенными индивидами» [2, с. 45]. Однако в исследовании в области менеджмента, по нашему мнению, необходимо сделать следующий шаг: признать важную роль механизмов доверия. Производственные коллективы, отношения в которых проникнуты доверием, как нами было показано ранее [3], в большей мере способны достигать поставленных целей. Это означает, что доверие относится к наиболее ценным ресурсам организации.

Для развития представлений о труде, по мнению Г.Я. Ракитской, «... требуется не только обобщать новые явления и тенденции в труде..., как это и делают обычно исследователи... Требуется в должной мере... увязать изучение социально-трудовых проблем с происшедшими, происходящими и предстоящими сдвигами в общественном устройстве» [4, с. 16]. В.Л. Иноземцев в этой связи обращает внимание, что общество, вступившее в новое тысячелетие, характеризует три главных признака: «утрата человеком контроля над большинством значимых социальных процессов; возрастающая в связи с этим неопределенность и прогрессирующая незащищенность личности перед лицом неконтролируемых ею перемен; наконец, возникающее в таких условиях стремление человека отказаться от достижения перспективных целей ради получения немедленных результатов, что в конечном счете приводит к дезинтеграции как социальной, так и индивидуальной жизни. Как следствие, общество начала XXI века характеризуется, с одной стороны, стремительным усложнением экономических процессов, а с другой - все более явной фрагментированностью человеческого существования» [5, с. 7-19]. «Травмы больших перемен» [6], как их называет П. Штомпка, становятся тем глубже, чем больше длительность периода следующих один за другим быстрых общественных изменений. Вероятность того, что «у нас будут проблемы... из-за отсутствия предсказуемости окружения и четких указателей, как жить» [7, с. 30], в этих условиях существенно повышается.

О серьезных разломах в общественной жизни на наднациональном уровне и их природе свидетельствует термин «глобализация». «Понятие глобализации, - обращает внимание 3. Бауман, - описывает процессы, представляющиеся самопроизвольными, стихийными и беспорядочными» [8, с. 43]. Оно пришло на смену понятию «универсализации», «когда стало ясно, что установление глобальных связей и сетей не имеет ничего общего с преднамеренностью и контролируемостью, подразумевавшимися ею» [8, с. 10]. Действительно, события в современном мире «беспредельны и бесконтрольны, носят квазистихийный, незапланированный, непредвиденный, спонтанный и случайный характер» [8, с. 152] и термин «глобализация», по мнению 3. Баумана, возвещает об этом. Однако нестабильность, спонтанность не только транслируется с уровня общества до уровня отдельной организации, но и имеет собственные источники на микроуровне, содействующие их формированию и быстрому распространению.

В современных «обществах риска» [9, с. 384], как их определил У. Бек, «... потребности производства меняются гораздо быстрее, чем человек способен освоить те знания и навыки, которые прежде считались необходимыми для участия в нем» $[9$, c. 166]. Этот и другие процессы вызывают «структурные сдвиги на рынке труда... такие как появление нетрадиционных форм занятости: временная работа, неполное рабочее время, телеработа и работа на дому... Увеличение доли в трудовых ресурсах самозанятых работников, выполняющих различные работы для разного рода заказчиков как физических, так и юридических лиц» [10, с. 10], порождают новые формы отношений в трудовой сфере, возникающие в рамках как традиционных, так и сорсингтехнологий (фрилансинг, аутсорсинг, инсорсинг, краудсорсинг и др.) [11]. 3. Бауман в связи с этим замечает, что «в условиях, когда занятость становится краткосрочной, ли- 
шается четких перспектив (не говоря уж о гарантированных) и тем самым превращается в эпизодическую... все правила, касающиеся игры в карьерное продвижение или увольнения, отменяются либо имеют тенденцию изменяться задолго до окончания игры» $[8$, c. 3].

Bсе перечисленные процессы «приводят к интенсификации риска как побочного или эффекта бумеранга человеческих действий и склоняет все большее количество исследователей к выводу, что «трудовая жизнь насыщается неопределенностью» [8, с. 30].

Этому способствует также новое качество капитала, именуемое некоторыми авторами терминами «мобильность», «летучесть» $[10,12]$. Вот что по этому поводу указывает 3. Бауман: «Избавившись от лишнего груза громоздкого оборудования и многочисленного персонала, капитал путешествует налегке, не более чем с ручной кладью: портфелем, портативным компьютером и сотовым телефоном. Это новое качество летучести сделало (долгосрочные) соглашения излишними и одновременно неразумными: они могут затруднять передвижение, тем самым сдерживая конкурентоспособность и ограничивая возможности повышения производительности» [8, с. 33].

Другие авторы, например Р. Сеннетт, соглашаясь с ним, заключает, что в складывающихся условиях «быстро исчезающие формы сотрудничества более полезны для людей, чем долгосрочные связи» [13, с. 24].

Некоторые исследователи заявляют о том, что мы приближаемся к «пределам, в которые заключена история рабочего движения» [14, с. 84], и утверждают, что формирующиеся в XXI в. тенденции ослабляют роль социальных процессов как на уровне общества в целом, так и на уровне предприятия. Поэтому они убеждены, что, например, «солидарность следует относить к числу теоретически невостребованных понятий» $[15$, с. 149]. Об этом, по мнению сторонников данной точки зрения, кроме вышеперечисленных, свидетельствуют также следующие факты:

- рабочие на сборочных конвейерах, представляющие собой, по выражению Р. Райча, «социальный субстрат рабочего движения» [16, с. 213], являются наиболее легко заменяемым элементом современных экономических систем. «Предъявляемые к ним требования, - отмечает 3. Бауман, - не предполагают ни каких-либо особых навыков, ни искусства общения с клиентами, и именно поэтому таких людей легче всего заменить... Они понимают, что вполне заменимы, и потому видят мало смысла в каком-то прочном привязывании себя к рабочему месту... или увязыванию своих жизненных целей с его возможным будущим» [8, с. 35];

- по сравнению со свободно перемещающимся в условиях глобализации капиталом, рабочие, занятые в конвейерном производстве, «придавленные к земле, обездвиженные... остаются локализованными. По этой причине они обезоружены и беззащитны... В такой ситуации, будучи или стремясь быть разумными людьми, они не хотят подвергать себя риску борьбы. Они едва ли превратят свои жалобы в политическую проблему и обратятся к властям предержащим за компенсацией» [8, с. 36];

- рост материальной обеспеченности трудящихся усиливает стремление каждого работника «самому решать свои личные трудовые проблемы» [10, с. 11].

Ф. Фукуяма, обращаясь к утверждению «процесс индустриализации, и особенно развитие серийного производства, неизбежно приводит к... фактической ликвидации ответственных и доверительных взаимоотношений на рабочих местах» [2, с. 364], высказываемому, помимо вышеперечисленных, и другими авторами, характеризует его лишь как «расхожее мнение, которое существует на протяжении долгих лет» [2, с. 364-365]. Заметим также, что не все из тех, кто указывает на происходящее ослабление социальности, являются действительно последовательными сторонниками данной точки зрения, чего, 
к сожалению, не замечают их рецензенты и критики. Так, В.И. Пантин пишет: «В своей книге Бауман последовательно рассматривает различные стороны жизни современного человека и всюду обнаруживает... распад общественных связей» [17]. Однако внимательный анализ показывает: 3. Бауман не утверждает, что специфической особенностью настоящего времени является ослабление социальности, вызванное стихийностью как новым качеством протекающих процессов. В противном случае, это свидетельствовало бы о непоследовательности занятой им позиции. Действительно, если следовать логике ряда современных авторов, приписываемой и 3. Бауману, то тогда первая половина XX в. также должна рассматриваться ими как период ослабления социальности, ведь согласно результатам исследования «феномена бюрократии», выполненного и опубликованного в первой половине 1960-х годов М. Крозье, в глазах тех, кем бюрократия в начале прошлого века управляла, бесчисленное количество правил выглядело беспорядочным и невообразимым хаосом [18, с. 320].

3. Бауман опирался в своем исследовании на вывод, к которому ранее пришел П. Бурдье, о том, что в настоящее время «угасает тяга к коллективным действиям» $[19$, с. 97]. Этим, по нашему мнению, объясняется излишняя радикальность его позиции в некоторых разделах опубликованной им монографии. Однако ему также известна точка зрения А. Пейрефитт, что «самой важной чертой общества, существовавшего до конца 1980-х годов, была уверенность: уверенность в себе, в других людях, в общественных институтах. Все три составные части такой уверенности были незаменимы они обусловливали друг друга: если убрать одну, две другие испытают чрезмерное напряжение (курсив автора)» [20, с. 524-516]. Поэтому за высказываниями 3. Баумана о происходящем «принижении значения социальных причин и коллективных действий» [8, с. 53] не следует упускать основную цель, которую поставил автор исследования: доказать, что «форма нашей социальности меняется, как и форма общества, в котором мы живем» [8, с. 181]. Достижение же ее невозможно без обращения к примерам «стремительного угасания старого искусства укрепления и упрочнения социальных связей» [8, с. 7].

Аналогичного взгляда придерживается и Ф. Фукуяма. Он не только отмечает, что «По мере того как технический прогресс захватывает все большие области, вместе с ним расширяются рынки и возникают новые формы организации. Под колесами этого локомотива гибнут прежние формы социальной жизни» [2, с. 507], но и указывает: «... социализированность... является важнейшей экономической добродетелью, заключающейся в том, что... люди, доверяющие друг другу и умеющие трудиться сообща, всегда легко справятся с новыми условиями и прибегнут к той форме организации, которая им будет удобна» [2, с. 519].

П. Штомпка также утверждает, что в формировании социальности ведущую роль играет доверие: «Когда происходит глубокая трансформация общественных систем, когда существовавшие ранее традиционные образцы, правила, роли, обязательства, сети связей подвергаются разрушению, а новые возникают постепенно, образующийся структурный и нормативный вакуум может компенсировать тот особенный «протез», каким является доверие» [12, с. 425].

В прошлом фундамент для повсеместного доминирования уверенности, как механизма организации общественной жизни, создавала стабильность социальных структур традиционного общественного устройства. Новая ситуация и попытка упорядочить социальные взаимодействия в условиях трансформационных изменений в обществе ведут к ослаблению роли уверенности и веры и возрастанию роли доверия в социальных взаимодействиях. Обращая внимание на указанные особенности доверия, А. Селигман за- 
мечает: «Дело в том, что центральным для определения доверия является то, что оно вовлекает человека в отношения, где действия, характер и намерения другого не могут быть удостоверены. При таком понимании человек вынужден доверять, наверное, лучше сказать, склонен доверять, - в случае, когда он не может знать, когда у него нет возможности точно понять или проверить другого, и потому у него нет выбора, как только доверять» [21, с. 17].

Из определения А. Селигмана следует, что понятие «доверие» не относится к прошлому, а лишь к будущему, не касается природных объектов, а лишь социальных. Что касается последнего утверждения, то на его правомерность указывает, например, неестественность ситуаций, связанных с доверием природе («я доверяю природе, что завтра будет прекрасная погода»). Вместе с тем феномен «доверие» не относится и к социальным объектам, если они находятся в ситуации полного контроля (очевидно, что в этом случае действие будет безусловно реализовано и без обращения к инструменту доверия). Во всех остальных ситуациях возникает потребность в доверии:

- в ситуации неполного контроля (при неуверенности в результативности контроля) - «разумное доверие»;

- в ситуации, когда невозможен контроль над происходящим, - «большое доверие».

В целом степень распространения феномена «доверие» на различные ситуации представлена в табл. 1.

Таблища 1. Сфера распространения феномена «доверие» Table 1. Sphere of the phenomenon of «trust»

\begin{tabular}{|c|c|c|c|c|}
\hline $\begin{array}{l}\text { Время } \\
\text { Time }\end{array}$ & $\begin{array}{c}\text { Вид объекта } \\
\text { Object type }\end{array}$ & $\begin{array}{c}\text { Ситуация полного } \\
\text { контроля (контроль } \\
\text { возможен) } \\
\text { Full control of the } \\
\text { situation (control is } \\
\text { possible) }\end{array}$ & $\begin{array}{c}\text { Ситуация неполного } \\
\text { контроля (нет уверенности } \\
\text { в результатах контроля) } \\
\text { Incomplete control of the } \\
\text { situation (there is no certain- } \\
\text { ty about the control results) }\end{array}$ & $\begin{array}{l}\text { Нет возможности кон- } \\
\text { троля над происходящим } \\
\text { (контроль невозможен) } \\
\text { There is no possibility } \\
\text { of control of the situation } \\
\text { (control is impossible) }\end{array}$ \\
\hline \multirow{2}{*}{$\begin{array}{c}\text { Прошлое } \\
\text { Past }\end{array}$} & $\begin{array}{c}\text { Природный } \\
\text { Natural }\end{array}$ & & & \\
\hline & $\begin{array}{c}\text { Социальный } \\
\text { Social } \\
\end{array}$ & & & \\
\hline \multirow{2}{*}{$\begin{array}{l}\text { Будущее } \\
\text { Future }\end{array}$} & $\begin{array}{c}\text { Природный } \\
\text { Natural }\end{array}$ & & & \\
\hline & $\begin{array}{c}\text { Социальный } \\
\text { Social }\end{array}$ & & $\begin{array}{l}\text { Разумное доверие } \\
\text { Reasonable trust }\end{array}$ & $\begin{array}{l}\text { Большое доверие } \\
\text { High level of trust }\end{array}$ \\
\hline
\end{tabular}

- ситуация, когда феномен «доверие» отсутствует;
- situation where the phenomenon of «trust» is absent.
- ситуация, когда феномен «доверие» присутствует;
- situation where the phenomenon of «trust» is present.

Исходя из изложенного, можно заключить, что усилению значимости категории «доверие» применительно к экономической сфере, помимо нарастания темпа изменений, способствуют также:

- растущее разделение труда (приводит к меньшей предсказуемости поведения лиц, занятых в едином трудовом процессе);

- делегирование полномочий [21] (увеличивает возможности выбора, находящиеся в распоряжении других); 
- растущая сложность и «непрозрачность» организационных и технических систем, как для персонала, занятого в них, так и для клиентов.

Итак, понятие «доверие» выдвигается в современной общественной мысли на роль ключевого в связи с пониманием невозможности организации без участия данного фактора устойчивых общественных отношений (Н. Луман, А. Селигман и др.) [22, 21$].$ Верно и обратное: утрата доверия ведет к разрушению социальных связей и институтов. В частности, она ведет к хорошо исследованному в экономической науке феномену отчуждения.

Перефразируя замечание Жака Барбале, высказанное им в отношении общественной жизни, можно утверждать, что деятельность каждой компании представляет собой «активное преобразование будущего в современность». Это требует постоянного поиска идей, продуктов, сотрудников, которые будут необходимы в осуществляемой ей деятельности. Принятие решений по указанному кругу вопросов означает для компании всякий раз «прыжок в неуверенность», который опирается на доверие. Петр Штомпка сравнивает в этом смысле доверие с «мостом над пропастью, ... позволяющим чувствовать себя уверенней в неопределенном мире» [12, с. 31].

В заключении статьи факторы, оказывающие прямое и косвенное влияние на усиление роли доверия в процессе трансформации форм социальности в организации (их также можно назвать рискообразующими факторами), представим в табличной форме (табл. 2).

\section{Таблица 2. Факторы, обусловливающие трансформацию социальности и усиление роли доверия в организации}

Table 2. Factors contributing to the transformation of sociality and the strengthening of the role of trust in the organization

\begin{tabular}{|c|c|c|}
\hline $\begin{array}{c}\text { Факторы первого уровня } \\
\text { First level factors }\end{array}$ & $\begin{array}{c}\text { Факторы второго уровня } \\
\text { Second level factors }\end{array}$ & $\begin{array}{c}\text { Факторы третьего уровня } \\
\text { Third level factors }\end{array}$ \\
\hline \multicolumn{3}{|l|}{$\begin{array}{l}\text { 1. Нарастание темпа } \\
\text { изменений в экономике } \\
\text { Growing pace of change in } \\
\text { the economy }\end{array}$} \\
\hline $\begin{array}{l}\text { 1.1. Глобализация } \\
\text { Globalization }\end{array}$ & $\begin{array}{l}\text { Резкий рост самопроизвольных, беспо- } \\
\text { рядочных и бесконтрольных процессов } \\
\text { Sharp increase in spontaneous, disordered } \\
\text { and uncontrolled processes }\end{array}$ & $\begin{array}{l}\text { Увеличение доли краткосроч- } \\
\text { ных контрактов } \\
\text { Increase in the share of short- } \\
\text { term contracts }\end{array}$ \\
\hline $\begin{array}{l}\text { 1.2. Частое изменение } \\
\text { технологии производства } \\
\text { Frequent changes } \\
\text { in production technology }\end{array}$ & & $\begin{array}{l}\text { Появление новых индивидуа- } \\
\text { лизированных видов трудовой } \\
\text { деятельности } \\
\text { Emergence of new individual- } \\
\text { ized types of work }\end{array}$ \\
\hline $\begin{array}{l}\text { 1.3. Быстрое изменение } \\
\text { потребностей } \\
\text { производства } \\
\text { Rapidly changing } \\
\text { production needs }\end{array}$ & & $\begin{array}{l}\text { Быстрое устаревание знаний и } \\
\text { навыков, необходимых для } \\
\text { участия в производстве } \\
\text { Rapid obsolescence of } \\
\text { knowledge and skills required to } \\
\text { participate in production } \\
\text { Частое изменение условий, } \\
\text { определяющих карьерное про- } \\
\text { движение } \\
\text { Frequent changes in the condi- } \\
\text { tions that determine career ad- } \\
\text { vancement }\end{array}$ \\
\hline
\end{tabular}




\begin{tabular}{|c|c|c|}
\hline $\begin{array}{l}\text { 1.4. Рост мобильности } \\
\text { капитала } \\
\text { Increased capital mobility }\end{array}$ & $\begin{array}{l}\text { Возрастание риска потери рабочего ме- } \\
\text { ста низкоквалифицированной рабочей } \\
\text { силой, вызванное ее невысокой терри- } \\
\text { ториальной мобильностью по сравне- } \\
\text { нию с высокой мобильностью капитала } \\
\text { Increased risk of job loss by low-skilled } \\
\text { labor force caused by its low territorial } \\
\text { mobility in comparison with high capital } \\
\text { mobility }\end{array}$ & $\begin{array}{l}\text { Расширение круга работ с ми- } \\
\text { нимально оговоренными га- } \\
\text { рантиями или их полным от- } \\
\text { сутствием } \\
\text { Expansion of the range of works } \\
\text { with minimum stipulated guaran- } \\
\text { tees or their complete absence }\end{array}$ \\
\hline $\begin{array}{l}\text { 2. Растущее разделение } \\
\text { труда } \\
\text { Growing division of labor }\end{array}$ & $\begin{array}{l}\text { Высокий риск потери рабочего места } \\
\text { работниками, занятыми в конвейерном } \\
\text { производстве и выполняющими простые } \\
\text { операции, в силу отсутствия у работода- } \\
\text { теля проблем с их заменой } \\
\text { High risk of job loss by workers employed } \\
\text { in conveyor production and performing } \\
\text { simple operations, due to the absence of } \\
\text { problems with the employer replacing them }\end{array}$ & $\begin{array}{l}\text { Снижение предсказуемости } \\
\text { поведения лиц, занятых в еди- } \\
\text { ном трудовом процессе } \\
\text { Reducing the predictability of } \\
\text { the behavior of persons em- } \\
\text { ployed in a single labor process }\end{array}$ \\
\hline $\begin{array}{l}\text { 3. Растущее делегирова- } \\
\text { ние полномочий } \\
\text { Growing delegation of au- } \\
\text { thority }\end{array}$ & \multirow[b]{2}{*}{$\begin{array}{l}\text { Увеличение объема прав, связанных с } \\
\text { принятием решений, находящихся в } \\
\text { распоряжении других, что ограничивает } \\
\text { возможности контроля и увеличивает } \\
\text { риски } \\
\text { Increasing the scope of decision-making } \\
\text { rights at the disposal of others, which limits } \\
\text { control and increases risks }\end{array}$} & \multirow[b]{2}{*}{$\begin{array}{l}\text { Ослабление увязки рабочими } \\
\text { достижения своих жизненных } \\
\text { целей со своим рабочим ме- } \\
\text { стом } \\
\text { Weakening workers' alignment } \\
\text { of achieving their life goals with } \\
\text { their workplace }\end{array}$} \\
\hline $\begin{array}{l}\text { 4. Растущая сложность и } \\
\text { «непрозрачность» орга- } \\
\text { низационных и техниче- } \\
\text { ских систем как для пер- } \\
\text { сонала, занятого в них, } \\
\text { так и для клиентов } \\
\text { The growing complexity } \\
\text { and «opacity» of organiza- } \\
\text { tional and technical sys- } \\
\text { tems both for the personnel } \\
\text { and for the clients }\end{array}$ & & \\
\hline $\begin{array}{l}\text { 5. Повышение уровня } \\
\text { жизни и вызванный этим } \\
\text { рост индивидуализма } \\
\text { Rise in living standards } \\
\text { and the resulting rise in } \\
\text { individualism }\end{array}$ & $\begin{array}{l}\text { Усиление неопределенности } \\
\text { Increasing uncertainty }\end{array}$ & $\begin{array}{l}\text { Стремление самостоятельно } \\
\text { решать свои личные трудовые } \\
\text { проблемы, а не коллективно } \\
\text { Desire to independently, rather } \\
\text { than collectively, solve their per- } \\
\text { sonal labor problems }\end{array}$ \\
\hline
\end{tabular}

Эти факторы по степени взаимосвязи между собой можно отнести к одному из трех уровней:

- факторы первого уровня - нарастание темпа изменений в экономике, усиливающееся разделение труда, растущее делегирование полномочий, сложность и «непрозрачность» организационных и технических систем. Они оказывают влияние на формирование факторов второго уровня, а потому могут быть названы также исходными или базовыми факторами;

- факторы второго уровня - различного рода неопределенности как результат влияния факторов первого уровня. Они создают условия, приводящие к неизбежной трансформации социальности как в деятельности организации, так и в общественной жизни в целом, в направлении усиления роли доверия и ослабления роли уверенности и веры;

- факторы третьего уровня - новые явления в деятельности персонала организаций. Они не только зависят от рискообразующих факторов предыдущего уровня, но и, в свою очередь, создают дополнительные риски. Таким образом, благодаря факторам 
третьего уровня, интенсифицируется процесс трансформации социальности и усиления роли доверия.

\section{СПИСОК ЛИТЕРАТУРЫ}

1. Taylor F. The Principles of Scientific Management. - London, UK: Harper \& Brothers, 1919. - 145 p.

2. Фукуяма Ф. Доверие: социальные добродетели и путь к процветанию. - М.: АСТ, 2008. - 730 с.

3. Каз Е.М. Доверие в организации и результативность деятельности: от модели к инструментам // Вестник Томского государственного университета. Экономика. - 2021. - № 53. - С. 111-122.

4. Ракитская Г.Я. Общая теория социально-трудовых отношений и перспективы их демократического регулирования в современной России: дис. ... д-ра экономических наук. - М., 2003. - 393 с.

5. Иноземцев В.Л. Введение: судьбы индивидуализированного общества. - М.: Логос, 2005. - 390 с.

6. Sztompka P. The trauma of social change: a case of postcommunist societies. - Dercley, CA: University of California Press, 2004. - 195 p.

7. Wilkinson I. Anxiety in a risk society. - London: Routledge, 2021. - 301 p.

8. Бауман 3. Индивидуализированное общество. - М.: Логос, 2005. - 390 с.

9. Beck U. Risk society. Towards a new modernity. - L.: Macmillan, 1992. - 384 p.

10. Соболевская А.А., Попов А.К. Постиндустриальная революция в сфере труда. - М.: ИМЭМО РАН, 2009. - 205 c.

11. Долженко Р.А. Новые формы трудовых отношений: уточнение понятий // Вестник Алтайского государственного аграрного университета. - 2014. - № 1 (111). - С. 168-173.

12. Штомпка П. Доверие - основа общества. - М.: Логос, 2012. - 440 с.

13. Sennett R. The corrosion of character: the personal consequences of work in the new capitalism. - New York: Norton, 1998. - $176 \mathrm{p}$.

14. Attali J. Chemins de sagesse. Traité du labyrinth. - Paris: Fayard, 1996. -84 p.

15. Барсукова С.Ю. Неформальная экономика: экономико-социологический анализ. - М.: Изд. дом ГУ ВШЭ, 2004. - 353 c.

16. Reich R. The Work of Nations. - New York: Vintage Books, 2020. - $331 \mathrm{p}$

17. Пантин В.И. Рецензия на книгу: 3. Бауман. Индивидуализированное общество // Научнообразовательный портал Высшей школы экономики. URL: http:/ecsocman.hse.ru/text/17992046/ (дата обращения 02.03.2021)

18. Crozier M. The bureaucratic Phenomenon. - Chicago: University of Chicago Press, 1964. - 320 p.

19. Bourdieu P. Contre-feux. Propos pour servir a la résistance contre l'invasion néo-libérale. - Paris: Raisons d'Agir, 1998. - 97 p.

20. Peyrefitte A. La société de confiance. Essai sur les origines du développement. - Paris: Odile Jacob, 1998. $616 \mathrm{p}$.

21. Селигман А. Проблема доверия. - М.: Идея-Пресс, 2002. - 256 с.

22. Luhman N. Trust and power. - New York: John Wiley, 1979. - 208 p.

Поступила 10.05.2021 г. 


\title{
TRANSFORMATION OF PERCEPTIONS ON THE ROLE OF SOCIALITY IN HUMAN RESOURCE MANAGEMENT AND THE CONCEPT OF TRUST
}

\author{
Evgeniya M. Kaz, \\ gk123a@mail.ru \\ National Research Tomsk State University, \\ 36, Lenin avenue, Tomsk, 634050, Russia
}

Evgeniya M. Kaz, Cand Sc., associate professor, National Research Tomsk State University.

The Relevance. In 1903 F. Taylor wrote that the reason for low labor productivity is thought and reasoning caused by the relations between entrepreneurs and workers. He believed that the intimate cooperation with the management and the help (which the workman should receive) from the management, would result on the average in nearly doubling the output of each man and each machine [1]. This problem formulated by $F$. Taylor and the posed question: "What other reforms ... could do as much toward promoting prosperity, toward the diminution of poverty, and the alleviation of suffering?», - have been exerting a powerful influence on the content of research programs in the field of management for more than a hundred years. However, many of F. Taylor's problems are still far from being solved. The period of socio-economic instability that the country is experiencing again today increases the need for tools that activate the ability and willingness of employees to perform the tasks assigned to them in a dynamically changing external and internal environment. The purpose: to analyze trends in changes in ideas about the role of sociality in the system of knowledge about human resource management. The method: comparison, generalization and systematization; an axiological approach that assumes the value dimension of the studied sociocultural phenomena. Results. The author presents a system of arguments indicating the strengthening of the role of trust both in the organization of public life in general, and in the activities of the organization, in particular. It is shown that «trust» helps to streamline social interactions in the conditions of transformational changes (increasing uncertainty and risks in the company's activities), when the possibilities of «confidence» and "faith» as mechanisms for organizing social life decrease. The growing role of the factor «trust» is also facilitated by the growing division of labor, delegation of powers, the complexity and «opacity» of organizational and technical systems. Conclusion: the factor of trust begins to play an increasingly important role in the functioning of the organization's management system.

Key words: Management organization, trust, human resources, transformation of sociality, sociopsychological aspects of management.

\section{REFERENCES}

1. Taylor F. The principles of scientific management. London, UK, Harper \& Brothers, 1919. 145 p.

2. Fukuyama F. Doverie: sotsialnye dobrodeteli i put $k$ protsvetaniyu [Trust: the social virtues and the creation of prosperity]. Moscow, AST Publ., 2008. 730 p.

3. Kaz E.M. Doverie v organizatsii i rezultativnost deyatelnosti: ot modeli k instrumentam [Trust within an organization and effectiveness of activities: from the model to the instrumentarium]. Vestnik Tomskogo gosudarstvennogo universiteta. Ekonomika, 2021, no. 53, pp. 111-122.

4. Rakitskaya G.Ya. Obshchaya teoriya sotsialno-trudovykh otnosheniy i perspektivy ikh demokraticheskogo regulirovaniya $v$ sovremennoy Rossii. Diss. Kand. nauk [General theory of social and labor relations and the prospects for their democratic regulation in modern Russia. Cand. Diss.]. Moscow, 2003. 393 p.

5. Inozemtsev V.L. Vvedenie: sudby individualizirovannogo obshchestva [Introduction: the fate of an individualized society]. Moscow, Logos Publ., 2005. 390 p.

6. Sztompka P. The trauma of social change: a case of postcommunist societies. Dercley, CA, University of California Press, 2004. 195 p. 
7. Wilkinson I. Anxiety in a risk society. London, Routledge, 2021. $301 \mathrm{p}$.

8. Bauman Z. Individualizirovannoe obshchestvo [Individualized society]. Moscow, Logos Publ., 2005. 390 p.

9. Beck U. Risk society. Towards a new modernity. London, Macmillan, 1992. 384 p.

10. Sobolevskaya A.A., Popov A.K. Postindustrialnaya revolyutsiya v sfere truda [Post-industrial revolution in the world of work]. Moscow, IMEMO RAN Publ., 2009. 205 p.

11. Dolzhenko R.A. Novye formy trudovykh otnosheniy: utochnenie ponyatiy [New forms of labor relations: clarification of concepts]. Vestnik Altaiskogo Gosudarstvennogo universiteta, 2014, no. 1 (111), pp. 168-173.

12. Shtompka P. Doverie - osnova obshchestva [Trust is the foundation of society]. Moscow, Logos Publ., 2012. $440 \mathrm{p}$.

13. Sennett R. The corrosion of character: the personal consequences of work in the new capitalism. New York, Norton, 1998. 176 p.

14. Attali J. Chemins de sagesse. Traité du labyrinth [The labyrinth in culture and society: pathways to wisdom]. Paris, Fayard, 1996. 84 p.

15. Barsukova S.Yu. Neformalnaya ekonomika: ekonomiko-sotsiologicheskiy analiz [Informal economy: economic and sociological analysis]. Moscow, GU VSHE Publ. house, 2004. 353 p.

16. Reich R. The work of nations. New York, Vintage Books, 2020. $331 \mathrm{p}$

17. Pantin V.I. Retsenziya na knigu: Z. Bauman. Individualizirovannoe obshchestvo [Individualized society]. Nauchno-obrazovatelny portal Vysshey shkoly ekonomiki. Available at: http://ecsocman.hse.ru/text/ 17992046/ (accessed 2 March 2021).

18. Crozier M. The bureaucratic phenomenon. Chicago, University of Chicago Press, 1964. 320 p.

19. Bourdieu P. Contre-feux. Propos pour servir a la résistance contre l'invasion néo-libérale [Proposal to serve the resistance against the neo-liberal invasion]. Paris, Raisons d'Agir, 1998. 97 p.

20. Peyrefitte A. La société de confiance. Essai sur les origines du développement [The trustworthy society. Essay on the origins of development]. Paris, Odile Jacob, 1998. 616 p.

21. Seligman A. Problema doveriya [The problem of trust]. Moscow, Ideya-Press Publ., 2002. 256 p.

22. Luhman N. Trust and Power. New York, John Wiley, 1979. 208 p.

Received: 10 May 2021. 